\title{
Thermal Stability of Porous Anodic Alumina Formed in Electrolytes with Surfactant Additives
}

\author{
V. ShulGOV* \\ Belarusian State University of Informatics and Radioelectronics (BSUIR), 6 Brovka Str., 220013, Minsk, Belarus
}

\begin{abstract}
Thermal stability of porous anodic alumina formed in various electrolytes is discussed. The bending deflection of the samples measured was converted to thermal stress. A model of transformation of the pore morphology during the re-anodizing in the electrolyte at the voltage increased relative to the voltage of the primary anodization is proposed.
\end{abstract}

DOI: 10.12693/APhysPolA.133.767

PACS/topics: 68.60.Dv

\section{Introduction}

Recently, anodized aluminum is widely used in microelectronics for the manufacturing switching plates, multiterminal packages for chips, multichip modules, various sensors, etc. One of the factors limiting the wide use of aluminum substrates with anodic alumina films (AAF) is the low thermal stability of the aluminum - $\mathrm{AAF}$ system. The problem is due to the fact that, according to various sources, the temperature coefficients of linear expansion of aluminum are 2.5 to 4.5 times higher than the temperature coefficients of linear expansion of anodic aluminum oxide. Therefore, at the high-temperature treatments during the microelectronic device fabrication, cracks appear in the anodic alumina films. The growth of these cracks can cause catastrophic failures of devices. Moreover, bending of the substrates causes difficulties in the photolithography execution.

A number of technical solutions allowing the thermal stability of the $\mathrm{Al} / \mathrm{AAF}$ system to be improved are known. For example, a thermal annealing to $477 \mathrm{~K}$ is recommended in [1], because the crack formation mechanism in the anodic oxide is attributed to the presence of associated water molecules in the film. The thermal stability of anodic coatings on aluminum is shown in another work [2] to be increased either by the anodization in the priority of acids: sulfuric $\rightarrow$ oxalic $\rightarrow$ phosphoric or by the oxidation in the same electrolyte by increasing the anodizing voltage. This is due to the increase in the size of cells and pores of the oxide with increase of voltage of anodic oxidation.

Prerequisites of the research were the data obtained from the theoretical analysis of the strain and stress emergence at the aluminum/alumina interface during the AAF growth $[3,4]$. In accordance with the theoretical estimates obtained, a zone of plastically deformed aluminum, where a part of elastic stress relaxes, arises at

*e-mail: shulgov@bsuir.by the aluminum/AAF interface during the $\mathrm{AAF}$ growth. This zone is equal to about three radius of the base of the anodic porous alumina cell. It would appear reasonable that the level of internal stress in the oxide due to high-temperature treatments would decrease as the zone of plastic deformation increases. Comparing the results of theoretical analysis and electron microscopic studies, it can be concluded that one way of reducing the thermal stress level can be a high voltage anodization for the fabrication of porous anodic alumina, since it is known that the cell and the pore diameters of porous oxide increase proportionally to the voltage applied to the anodization bath [5].

This is confirmed by the data of work [6], where the thermal stability of substrates was increased by the porous anodization in multicomponent electrolyte at voltages up to $170 \mathrm{~V}$. However, the pore diameters increase to $170-200 \mathrm{~nm}$ at that, adversely affecting the dielectric strength of oxide and quality of metallization layers deposited on such oxide. Therefore, the two-stage formation of porous oxide seems to be logical. First, a low-voltage anodization of aluminum substrate is carried out, then the anodizing electrolyte is changed and the aluminum substrate is anodized at high anodizing voltages. The choice of the electrolyte for the second anodizing stage is very important at that.

The research results given in [7] showed that the introduction of surfactant into the pore-forming electrolytes is one of the efficient methods of influence on kinetics of the anodic oxidation process. For example, the introduction of sodium dodecyl sulfate (SDS), which is an anionic surfactant, into the electrolyte based on phosphoric acid leads to a significant reduction in the oxide dissolution rate during the anodization and the increase in the anodizing voltage.

Referring to [8], the smallest dissolution of the alumina during the $\mathrm{Al}$ anodization and the best electrical properties of the oxide are obtained by two-step anodizing, namely: first in $2 \%$ oxalic acid at a voltage of $60 \mathrm{~V}$ and then in $4 \%$ phosphoric acid with $0.5 \mathrm{M}$ triethanolamine additive at a voltage of $200 \mathrm{~V}$. 


\section{Experimental}

The study of the thermal stability of the $\mathrm{Al} / \mathrm{AAF}$ system was made by measuring the bending deflection under heating. The $1.5 \mathrm{~mm}$ thick aluminum substrates made of commercially available alloy AMg-2 (Al containing $0.4 \% \mathrm{Fe}, 0.4 \% \mathrm{Si}, 1.8-2.8 \% \mathrm{Mg}$ and other impurities with total amount to $5 \%$ ) were used. After the chemical treatment in $50 \%$ aqueous sodium hydroxide solution and then in the nitric acid the $\mathrm{Al}$ substrates were ground and polished mechanically on one side. Next, the substrates were cut into the $120 \times 5 \mathrm{~mm}^{2}$ sized strips with the stamp. After degreasing, the samples were subjected to the thermal straightening at a temperature of $623 \mathrm{~K}$ for $3 \mathrm{~h}$. Before anodizing in the electrolyte investigated, nonworking side and the side surfaces of the substrates were protected with a layer of dense anodic alumina formed in the $1 \%$ citric acid electrolyte at the voltage of $200 \mathrm{~V}$ and a layer of photoresist. The protection mask was removed before measuring the bending deflection. The formation of anodic alumina films was carried out in the electrolytes shown in Table I.

As can be seen from Table I, the initial anodic alumina films were formed on the samples of all three types in the oxalic acid electrolyte. The film thickness was $50 \mu \mathrm{m}$, the anodization voltage was $60 \mathrm{~V}$, the electrolyte temperature was $293-303 \mathrm{~K}$, the anodization time was $120 \mathrm{~min}$.

TABLE I

Sample types studied

\begin{tabular}{c|c|c|c}
\hline \hline \multirow{2}{*}{$\begin{array}{c}\text { Sample } \\
\text { type }\end{array}$} & \multicolumn{3}{|c}{ Anodization in acid } \\
\cline { 2 - 4 } & $2 \%$ oxalic & $1 \%$ citric & $\begin{array}{c}4 \% \text { phosphoric with } \\
\text { triethanolamine }\end{array}$ \\
\hline I & + & - & - \\
II & + & + & - \\
III & + & - & +
\end{tabular}

The samples of the second type after washing were anodized in $1 \%$ citric acid at a voltage of $200 \mathrm{~V}$ until the reduction of the current through the oxide 50-60 times relative to the initial value.

The samples of the third type after washing were anodized in $4 \%$ phosphoric acid with the $0.5 \mathrm{M}$ triethanolamine additive. The anodization voltage was $200 \mathrm{~V}$, the electrolyte temperature was $288-293 \mathrm{~K}$, and the current density was $0.4-0.5 \mathrm{~mA} / \mathrm{cm}^{2}$. Knowing the anodizing constant $K_{a}$ (in $4 \% \mathrm{H}_{3} \mathrm{PO}_{4} K_{a}=1 \mathrm{~nm} / \mathrm{V}$ ) [5], the thickness of the barrier layer can be estimated as: $h_{b}=K_{a} U_{a}$. In our case $h_{b}=200 \mathrm{~nm}$. Therefore, the time of the aluminum anodization in $4 \% \mathrm{H}_{3} \mathrm{PO}_{4}$ with the $0.5 \mathrm{M}$ triethanolamine additive should be selected so that the barrier layer has the thickness of $0.2 \mu \mathrm{m}$. The anodizing time was fitted experimentally and was $\approx 20 \mathrm{~min}$. The thickness of the film was monitored using the interferometer MII-4. A comparative assessment of the thermal stress level in the oxide films of three types were conducted by measuring the bending deflection. To this end, two samples were placed into a thermostatic chamber (Fig. 1), each of which was rigidly fixed at one end. One sample freely bent during heating and cooling, the second one was assigned to $\mathrm{CR}-\mathrm{Ni}$ thermocouple. Heating of samples was carried out by heating a chamber with a spiral. The heating and cooling rates were $0.3-$ $0.4 \mathrm{deg} / \mathrm{s}$. The bending deflection of the sample studied was measured by the deviation of the free end by the countdown through the lens with measuring scale using the MBS-9 microscope.

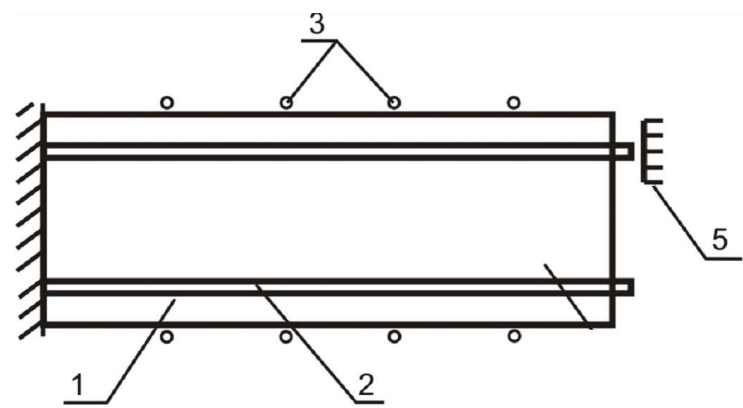

Fig. 1. A schematic diagram of the device for the bending deflection measurement: 1 - camera, 2 - samples, 3 - heater, 4 - thermocouple, 5 - measuring scale.

\section{Results and discussion}

Referring to [9], the stress caused by the difference in thermal linear expansion coefficients of the substrate and the film is expressed as:

$$
\sigma=\frac{\left(\alpha_{A l}-\alpha_{o x}\right) \Delta T}{h_{0}(1-\nu)\left(\frac{1}{E_{0} h_{0}}+\frac{1}{E_{2} h_{2}}\right)},
$$

where $\alpha_{o x}$ and $\alpha_{A l}$ are the linear thermal expansion coefficients of aluminum and alumina, $\nu$ is the Poisson ratio of the substrate, $\Delta T$ is the increment of temperature, $E_{0}$ is the Young modulus of the alumina, $E_{2}$ is the Young modulus of aluminum, $h_{0}$ and $h_{2}$ are the thicknesses of the film and substrate correspondingly.

The calculation of internal stresses in the temperature range from 298 to $623 \mathrm{~K}$ shows that for all types of samples values $\sigma$ should be approximately $2 \times 10^{9} \mathrm{~N} / \mathrm{m}^{2}$ and the deflection must be the same, which contradicts the data obtained by measuring the bending deflection.

Figure 2 shows the dependence of the bending deflection for the samples of the three types during heating and cooling.

As can be seen from Fig. 2, the greatest bending deflection is observed for the samples of the first type. The curve is almost linear in the temperature range of 283$523 \mathrm{~K}$, suggesting that a plastic deformation of the aluminum and any changes in the oxide (cracks) were not observed.

For the samples of the second type (curve 2 in Fig. 2a) a linear increase in the deformation is observed in the temperature range from 323 to $523 \mathrm{~K}$. Further, to $563 \mathrm{~K}$ 


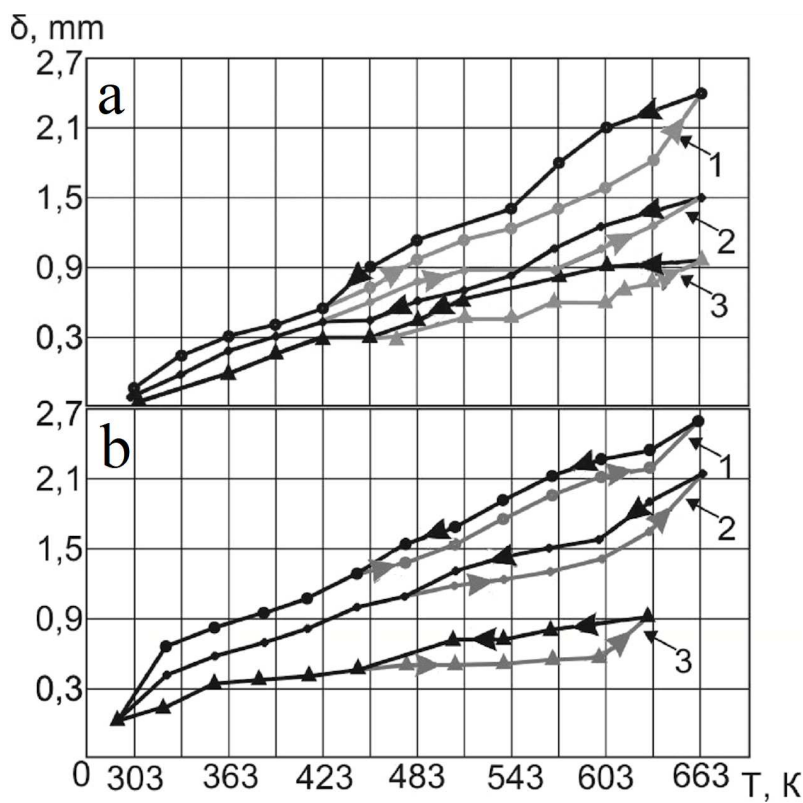

Fig. 2. The temperature dependence of the bending deflection for three types of samples: (a) before thermal annealing, (b) after thermal annealing. $1-2 \%$ oxalic acid, $2-2 \%$ oxalic acid and $1 \%$ citric acid, $3-2 \%$ oxalic acid and $4 \%$ phosphoric acid with triethanolamine additive.

the bending deflection does not increase with a subsequent slight increase. A reverse curve almost coincides with the direct one, indicating the elastic nature of the stresses.

The deformation of the third type samples shows significant qualitative and quantitative differences from the samples of the first two types. The growth of the bending deflection takes place stepwise, as shown in Fig. 2a, curve 3 , and has a minimal absolute value. The reverse curve demonstrates almost a linear reduction of the bending deflection.

For the explanation of significant differences curves $\delta=f(T)$ let us consider in more detail the processes occurring at the $\mathrm{Al} / \mathrm{AAF}$ interface as shown in Fig. 3.

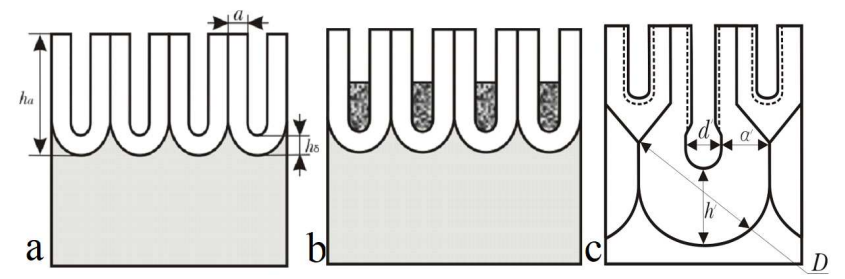

Fig. 3. Morphology of the porous anodic alumina obtained using different anodizing modes: (a) porous $(50 \mathrm{~V}),(\mathrm{b})$ porous $(50 \mathrm{~V})$ with further porous $(200 \mathrm{~V})$; (c) porous $(50 \mathrm{~V})$ with further dense $(200 \mathrm{~V})$ anodization.

As seen from Fig. 3a, the cell of porous anodic alumina is characterized by a diameter $D$, a pore diameter $d$, a thickness of the pore wall $a$ and a certain thickness of the barrier layer $h$ when the film thickness is $h_{0}$. The film of porous anodic alumina with such the structure was obtained by anodizing in the oxalic acid electrolyte. In the case of the subsequent oxidation in the citric acid electrolyte, a thickening of the barrier layer and pore filling with oxide occurs, as shown in Fig. 3b [10].

When aluminum is anodized in the electrolyte poorly dissolving alumina, the pore structure appears in another way. When the anodization voltage increases after the moment corresponding to the electrochemical breakdown, the pore structure should be changed as shown in Fig. 3c: the diameters of cells $D$ and poresd increase, the barrier layer $h$ and the pore walls $a$ thicken. At the same time the process of the chemical dissolution of pore walls begins. Referring to [11], the mentioned process takes place not in all the pores. The growth of the pores, which during the electrochemical breakdown were in the conditions when the electrochemical dissolution in them is difficult in comparison with nearby, is suppressed.

Figure 4 demonstrates the SEM picture of the crosssection of the anodic alumina film grown on the aluminum foil A99 (99.99\% Al). The undeveloped pore (a) and slightly expanded pore (b) with a thickened barrier layer and increased cell size are observed.

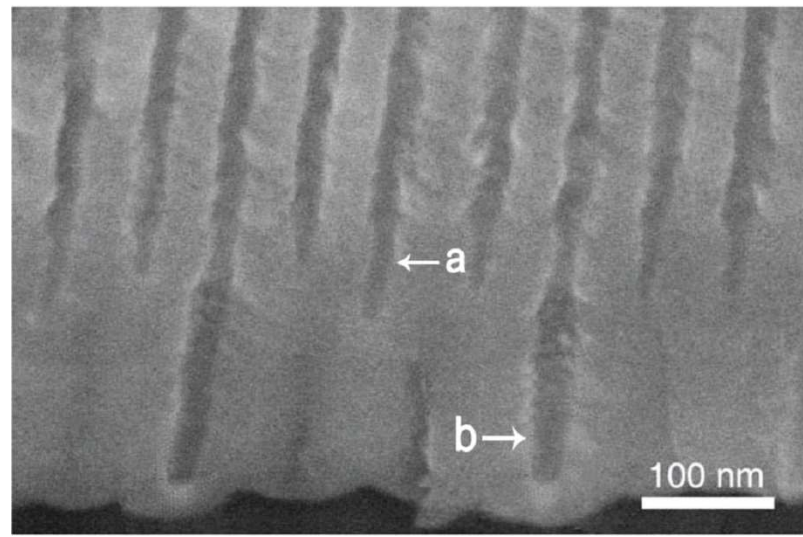

Fig. 4. SEM picture of the cross-section of the anodic alumina film.

When anodized in phosphoric acid electrolyte with the triethanolamine additive at a voltage of $200 \mathrm{~V}$, the diameter of the hexagonal cells increases 3-4 times in comparison with the diameter of the oxide cells formed in oxalic acid, resulting from the transformation of the $\mathrm{Al} / \mathrm{AAF}$ interface at the last stage of anodizing.

Thus, in the temperature field a zone of plastically deformed aluminum is in the aluminum substrate with single sided anodic alumina coating and the more extensive the area is, the greater the relaxation of internal stress and less bending.

After the measurements of the bending deflection, the samples of all three types were subjected to a threefold cyclic heat treatment in the temperature range of 298$553 \mathrm{~K}$ with the subsequent re-measurement of the bend- 
ing deflection. The results are presented in Fig. 2b. As can be seen from Fig. 2b, for the samples of I and II types the deflection increases, while for the samples of III type the bending deflection decreases relative to the original measured. After the heat treatment of samples of the type III, the bending deflection in the temperature interval $433-603 \mathrm{~K}$ is almost flat, while for the not heat-treated samples it is stepped. The reverse course of the curve is expressed by an almost linear decrease in the deflection.

This result can be explained as follows [12]. After several cyclic loadings compressive stresses take maximum values that exceed the maximum stress occurring at the first thermal loading. For the samples of III type the relaxation of this type of stress occurs due to the vastness of the zone of plastic deformation while for the samples of I and II types this does not happen.

\section{Summary}

Thus, the sequential anodizing of aluminum first in the oxalic acid electrolyte and further in the electrolyte of phosphoric acid with the addition of triethanolamine at $200 \mathrm{~V}$ allows the stress at the Al-AAF interface resulting from the high temperature treatments to be reduced significantly.

\section{References}

[1] F. Ostermann, Aluminium Application Technology, Springer-Verlag, Berlin 2007 (in German).

[2] V. Sokol, V. Shulgov, Solid State Phenomena 230, 14 (2015).

[3] D.H. Bradhurst, J.S.L. Leach, Trans. Brit. Ceram. Soc. 62, 793 (1963).

[4] D.H. Bradhurst, J.S.L. Leach, J. Electrochem. Soc. 113, 1245 (1966).

[5] G.D. Sulka, Nanostructured Materials in Electrochemistry, Wiley-VCH, Weinheim 2008, p. 1.

[6] Patent DE10361888B3 Anodisierverfahren für Aluminiumwerkstoffe, C25D 11/12, 22.09.2005.

[7] H. Kaur, L. Sharma, M. Kushwaha, ECS J. Solid State Sci. Technol. 5, M154 (2016).

[8] V. Schulgov, V. Sokol, in: 18. Conference Solid State Analysis, Wien, Ed. G. Friedbacher, Wien 2015, P28.

[9] A.J. Fletcher, Thermal Stress and Strain Generation in Heat Treatment, Elsevier Applied Science, London 1989.

[10] E. Ignashev, E. Gurskaja, V. Shulgov, Microchim. Acta 156, 147 (2007).

[11] G. Patermarakis, K. Moussoutzanis, J. Electroanal. Chem. 659, 176 (2011).

[12] J. Chakrabarty, Theory of Plasticity, Elsevier Butterworth-Heinemann, Oxford 2006. 